\title{
Climate or rural development policy?
}

\author{
Sándor Kerekes \\ Professor, Corvinus University of Budapest, Department of Environmental Economics and \\ Technology \\ E-mail: sandor.kerekes@,uni-corvinus.hu
}

Szilvia Luda

PhD student, Corvinus University of Budapest, Department of Environmental Economics and

Technology

E-mail: szilvia.luda@uni-corvinus.hu

Being heavily energy dependent, it is not much of a surprise that Europe pays special attention to reducing the use of fossil fuels. Each one of the ten new member states is characterized by relatively low per capita energy consumption and relatively low energy efficiency, and the share of renewables in their energy mix tends to be low, too. The paper examines the problem when policy measures create a decrease in environmental capital instead of an increase. In this case it hardly seems justified to talk about environmental protection. The authors describe a case of a Hungarian rapeseed oil mill which would not be of too much interest on its own but given that almost all similar plants went bankrupt, there are some important lessons to learn from its survival. The enterprise the authors examined aimed at establishing a micro-regional network. They completed a brown-field development to establish a small plant on the premises of a former large agricultural cooperative. By partnering with the former employees and suppliers of the sometime cooperative, they enjoyed some benefits which all the other green-field businesses focusing on fuel production could not. The project improved food security, energy security and population retention as well.

Keywords: renewable energy, game theory, sustainable development in rural regions, EU climate policy

JEL-codes: P48, R11, Q16

\section{Unresolved problems of the globalized world}

Some global environmental problems do not harm human health directly, thus it is rather hard to generate social support to act against them. Often, even scientists are divided over the nature of the issue. Results can only be achieved through radical changes. The executive director of Stockholm Resilience Centre, Johan Rockström, and his co-authors, in their article on planetary boundaries published in Nature (Rockström et al. 2009) mention two global problems we need to actively pay attention to. These are climate change and the rapid loss of biodiversity. A common characteristic of these issues is that instead of threatening the health of individuals, they are actually endangering the stability of the entire ecosystem. "If one boundary is transgressed, then safe levels for other processes could also be under serious risk, they caution". Humans not being directly affected, these environmental problems tend to be severely affected by the so-called discounting phenomenon. Present efforts are required in order to avoid a potential future catastrophe. The material consumption of present generations should be decreased to provide more favorable living standards for future generations. We are, however, unable to overcome "mainstream" logic. We have got used to simply having to 
estimate the present value of any risk-prevention project and we fail to recognize that this is not some regular economic type of risk but a potential catastrophe threatening the existence of the human race. We should act in order to avoid this catastrophe and realize that present value calculations are not a relevant analytical method in this very case. "Survival" may justify material expenses of any magnitude. This is something we all know when we or our beloved ones are affected, yet we all keep on hoping that cost-benefit analyses are relevant to others' lives and especially to the survival of "mankind" in general.

The attention of humanity and especially politicians should be directed towards slow variables and harmful accumulation processes. This is, however, a difficult task as according to the logic of civil democracies, politicians tend to be concerned with the issues of the highest media value. The Hungarian red sludge catastrophe in 2010 caught the attention of the world (that is: the media), raised people's sympathy and therefore whole societies started to act. The extinction of some unknown species, however, only bothers the most sensible environmentalists - who constitute 2-5 percent of the Earth's population at most. UN world conferences, leading from the one in Stockholm in 1972 to the Copenhagen (2009) or the Cancun (2010) summit, all lead to the same conclusion that neither climate change nor loss of biodiversity is a problem that mankind will be able to cope with. Obviously, there is a need for radical change in what our "usual" way of life appears to be. We will have to change our values, indeed, our entire culture, in order to earn a chance to avoid such threats.

According to the UNEP definition, ${ }^{1}$ sustainable consumption does not mean less consumption, but rather more efficient consumption. This definition is a true reflection of the conceited arrogance of the modern world. Obviously, consumption should be more efficient, but there is no doubt it should be reduced in volume too. ${ }^{2}$ The Earth will not be able to host an ever growing population of 7-9 billion people, especially not with everyone wanting to consume more at a personal level as well. Even more certain than this fact is that populations will not fit within the present political borders (protected, of course, by an unimaginable range of weapons). Mankind can only further expand at the expense of other species, which, in the long run, makes the biosphere very vulnerable, even though it is absolutely essential to human life.

Experience has shown that mankind is only willing to change if it is unsatisfied with the status quo. More than half of the Earth's population is starving and thus obviously unsatisfied, but these individuals consider the so-called developed world to be a more desirable model, even though it is nothing to be followed as it is the very source, rather than the solution, to the problem. Instead of marginal innovations, it is radical system innovations that we need in the next fifty years in order to change current trends already known to be unsustainable.

A key element in sustainable development strategies is solving the energy problem. Table 1 reflects the simplified views of the EU professional elite on the world and on energy consumption, showing expected changes until 2050 from an energy management perspective. The data are from the World Energy Technology Outlook (WETO) project. While world population is expected to grow by around 30 percent, that of Europe remains almost

\footnotetext{
${ }^{1}$ Sustainable consumption is not about consuming less, it is about consuming differently, consuming efficiently, and having an improved quality of life (UNEP 1999).

${ }^{2}$ A much better definition were accepted in a workshop in Kabelvåg: „Sustainable consumption means we have to use resources to meet our basic needs and not use resources in excess of what we need". (Participant definition, see IIED 1998) Unfortunately this is not a definition which is widely discussed and accepted by the policymakers.
} 
unchanged. GPD per capita is expected to increase to about 2.5 and 2.67 times its present value in Europe and in the world, respectively. These figures, however, are most probably unreal, as social stability and international security would require some kind of convergence at a worldwide level, not only in Europe (European Commission 2005).

Table 1. Population and economic growth (WETO-H2 project assumption)

\begin{tabular}{|l|c|c|c|c|c|}
\hline Key indicators World & $\mathbf{1 9 9 0}$ & $\mathbf{2 0 0 1}$ & $\mathbf{2 0 1 0}$ & $\mathbf{2 0 3 0}$ & $\mathbf{2 0 5 0}$ \\
\hline Population (Billions) & 5.2 & 6.1 & 6.8 & 8.1 & 8.9 \\
\hline Per capita GDP (€05/cap) & 5300 & 6400 & 8100 & 12100 & 17100 \\
\hline Key indicators Europe & \multicolumn{5}{|l|}{} \\
\hline Population (Millions) & 564 & 588 & 599 & 606 & 586 \\
\hline Per capita GDP (\$95/cap) & 14849 & 17533 & 21124 & 31496 & 43005 \\
\hline Primary Production (Mtoe) & 1115 & 1196 & 1284 & 1158 & 1593 \\
\hline Coal, lignite & 393 & 240 & 220 & 218 & 225 \\
\hline Oil & 224 & 313 & 309 & 113 & 86 \\
\hline Natural gas & 190 & 244 & 310 & 203 & 210 \\
\hline Hydro, geothermal & 44 & 54 & 55 & 60 & 63 \\
\hline Biomass and wastes & 53 & 87 & 131 & 188 & 283 \\
\hline Wind, solar & 0 & 3 & 11 & 49 & 101 \\
\hline Electricity Cons./capita (kWh/cap) & 4206 & 4995 & 5787 & 8176 & 11839 \\
\hline Transport fuels per capita (toe/cap) & 0.55 & 0.65 & 0.62 & 0.65 & 0.63 \\
\hline
\end{tabular}

Source: European Commission (2005)

The one and only favorable message from this forecast is that these achievements seem to "only" require an approximate 33 percent growth in primary energy production. Experts estimate that hydrogen technology may be sufficient to cover our energy needs until 2050.

\section{EU efforts to contain the impacts of climate change}

Being heavily energy dependent, it is not much of a surprise that Europe pays special attention to reducing the use of fossil fuels and to exploring and promoting the employment of renewable energy sources. In order to fight climate change, member states made the following commitments for 2020 at the European Council Summit of 8-9 March 2007:

- reduce carbon-dioxide emissions by 20 percent;

- improve energy efficiency by 20 percent;

- increase the share of renewable energy in the EU energy mix to 20 percent;

- increase the share of biofuels to 10 percent.

The decision was criticized even before it was made. Not only for being premature and lacking any and all background calculations but also because these amounts are simply not sufficient from a climate change point-of-view. Green NGOs (like Friends of the Earth) claim a 60-70 percent reduction in emissions is needed. According to the above-cited WETO project, Europe will only achieve 10 percent by 2050 . The 20 percent reduction, thus even contradicts the EU's own professional forecasts and what is more, is quite marginal in importance considering climate change. The best we can say about these commitments is that they might indicate that the EU believes climate change to be a real threat and that they are ready to make efforts to avoid a catastrophe. The Copenhagen Climate Conference did not bring anything new to the table either. The only thing the world's countries could agree on was that they should keep making the necessary efforts.

European emission reduction achievements have been very contradictory. Table 2 shows commitments vs. actual data on the energy consumption and carbon dioxide emissions of fifteen countries (using a ranking of the top thirty). 
Table 2. Energy consumption ranking of certain European countries (from amongst the first 30)

\begin{tabular}{|l|c|c|c|c|}
\hline & $\begin{array}{l}\text { Per capita } \\
\text { consumption }\end{array}$ & $\begin{array}{l}\text { Consumption per unit } \\
\text { GDP }\end{array}$ & $\begin{array}{l}\text { Distance from carbon dioxide } \\
\text { emission target }\end{array}$ & $\begin{array}{l}\text { Share of } \\
\text { renewables }\end{array}$ \\
\hline Austria & 19 & 5 & 18 & 4 \\
\hline Belgium & 25 & 18 & 10 & 15 \\
\hline Bulgaria & 6 & 29 & 5 & 28 \\
\hline Czech Republic & 16 & 28 & 1 & 2 \\
\hline Denmark & 17 & 4 & 11 & 24 \\
\hline Estonia & 16 & 28 & 21 & 3 \\
\hline Finland & 28 & 25 & 18 & 14 \\
\hline France & 23 & 11 & 8 & 26 \\
\hline Germany & 22 & 10 & 9 & 16 \\
\hline Hungary & 8 & 17 & 29 & 9 \\
\hline Ireland & 20 & 3 & 15 & 22 \\
\hline Italy & 11 & 1 & 2 & 10 \\
\hline Latvia & 3 & 20 & 6 & 20 \\
\hline Norway & 27 & 12 & & Source: Eurostat \\
\hline Poland & 5 & 22 & & 26 \\
\hline
\end{tabular}

It is quite apparent that the commitments mentioned, while requiring serious efforts from some of the countries, do not constitute a problem at all to some others. Surprisingly enough, Finland, though usually considered a pioneer of environmental protection, lags far behind not only because of its high per capita consumption but also because of its per unit GDP consumption. Something similar applies to Norway as well, even though both countries boast very favorable advantages concerning renewable energy production thanks to their hydropower resources.

These rankings also confirm the well-known fact that rich countries tend to have higher per capita but lower per unit GDP energy consumption while the exact opposite applies to poor states. What is more, these trends have been unchanged for a long time, as illustrated by Figure 1.

Figure 1. Changes in countries' carbon dioxide emissions and GDP between 1980 and 2002

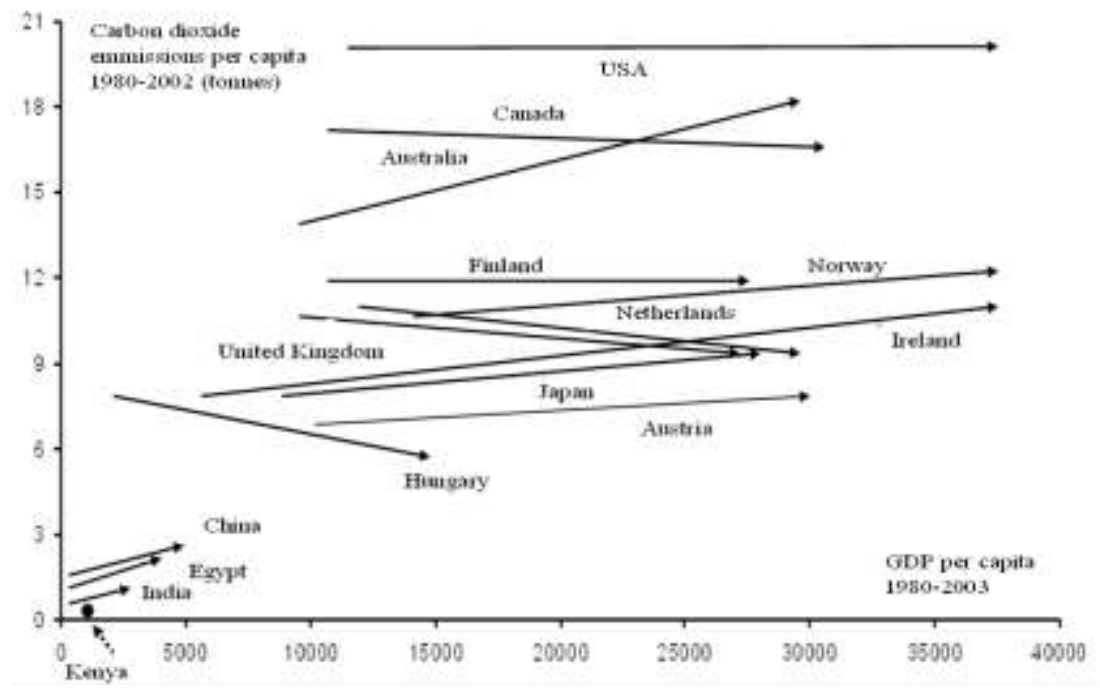


Figure 2. Changes in countries' per capita carbon dioxide emissions between 1997 and 2007

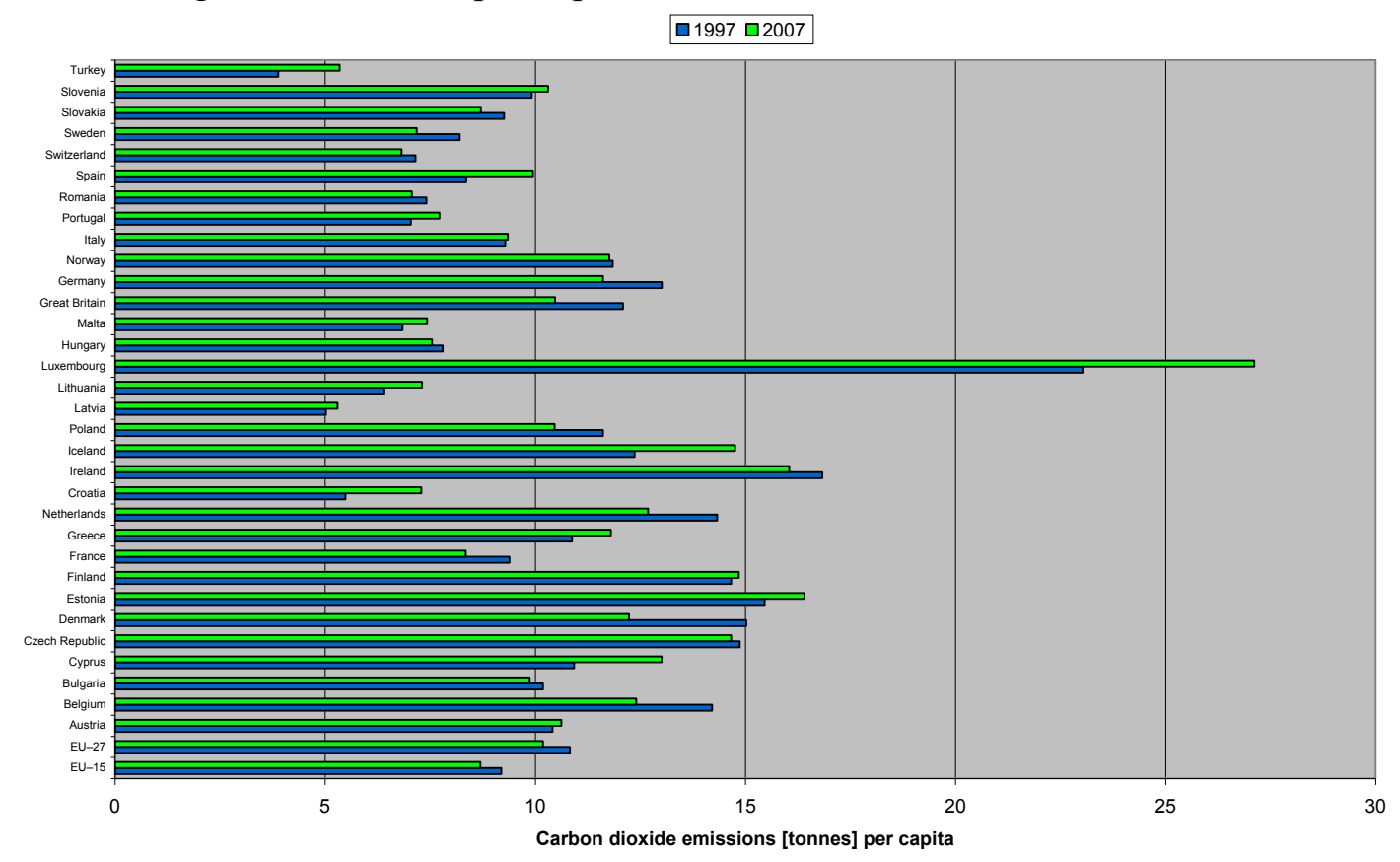

Source: Eurostat

These trends have not changed between 1997-2007 either (Figure 2) and are not too much of a surprise, but according to Figure 1 and Table 2 the aforementioned "uniform" commitment of the EU states is rather hard to interpret. The "everyone has to lower their carbon dioxide emissions by 20 percent" rule, though indeed indiscriminate it might seem even to a layman's eyes - it is actually not. The beneficiaries of the "free" use of the environment are still going to enjoy the same benefits. Per capita energy consumption in Finland is twice that of Hungary, and a 20 percent reduction would not change this ratio at all. The economy is running pretty well at a consumption rate of 9.6 tons/capita, yet its operation would be far less smooth at 4.8 tons/capita. It would be much more fair and logical if the countries lagging far behind the set targets (e.g. Finland, Ireland) committed themselves to more serious reductions, while those already closer to the target should only have to achieve smaller cutbacks.

Each one of the ten new EU member states is characterized by relatively low per capita energy consumption and relatively low energy efficiency, and the share of renewables in their energy mix tends to be low too. This situation clearly calls for energy policies which improve both energy efficiency and the share of renewables in the energy mix. It is not only carbon emissions but also energy security and the non renewable character of fossil fuel reserves which justifies increased interest in opportunities to employ biomass or wind energy. Many consider the renewable energy industry a potentially lucrative area for investment.

\section{Chances for decentralized energy in a world governed by economies of scale}

The principle of federalism, asserting that centralized control is inherently suboptimal, is very well-known amongst environmentalists (see for example Oates 1977 or Smith - Schwabe Mansfield 1999 for the idea of environmental federalism). To make it worse, the dominance of economic interests is especially strong in energy matters, pushing environmental interests to the background. The EU's energy policies consistently contradict the principle Hubbard formulated in 1991: "The sooner consumers and those governing the market are faced with the real cost of energy, the better. This definitely means higher prices but that will urge the market to implement more and more efficient, cost effective and environmentally friendly 
methods" (Hubbard 1991). EU subsidies repeatedly ignore this well-established principle - in an inconsistent way, to make things worse.

One should realize that the present subsidy system is not sustainable in the long run as it makes electric energy unreasonably expensive. In Hungary, for example, the share of baseload power plants (lignite and nuclear) is exceptionally high within the electricity generation sector. The high share of nuclear energy imposes some fundamental restrictions upon renewable energy production which must inevitably be taken into account to ensure the sustainability of the entire system.

All green NGO's find it desirable to support the spread of so-called "green energy", though there are debates about the exact details. Some opt for wind power, some for biofuels while others demand increased subsidies for geothermal energy production.

\section{Decision dilemmas about renewable energy sources}

In Table we describe three cases which tend to divide the public. "Stakeholders" (entrepreneurs, government, NGO's and others) are all part of a so-called "decision game" and, not having read the book of John von Neumann, ${ }^{3}$ they believe that the objective of the "game" is to win. Whereas one should rather decide first what kind of game they are actually playing. In our examples, the stakeholders and especially the government and the NGOs believe the game to be about environmental protection. Those in support of wind turbines, of increasing the mandatory bioethanol or biodiesel mixing rate and of the natural gas program are acting for a good cause by supporting environmental protection. Both the government and NGO's are convinced that the purpose of using renewable energies is to slow down the exhaustion of natural resources and to reduce the emission of greenhouse gases. Both of these objectives can be related to sustainable development and environmental protection. Thus the decision "game" appears to be about environmental protection. But is it really? Let us take a look at what the environment "gains" and how environmental conditions improve through the use of wind power, bioethanol or a natural gas program.

Table 3. Energy and climate change related "games" between NGOs and the economy

\begin{tabular}{|c|c|c|}
\hline $\begin{array}{l}\text { Replacing fossil fuels or reducing their } \\
\text { negative effects }\end{array}$ & $\begin{array}{l}\text { NGOs believe the game to be } \\
\text { about... }\end{array}$ & The game is actually about... \\
\hline 1. Biofuels & $\begin{array}{l}\text { Renewable energies to slow down } \\
\text { resource exhaustion, reduce carbon } \\
\text { emission }\end{array}$ & $\begin{array}{l}\text { Rural development, energy } \\
\text { security }\end{array}$ \\
\hline 2. Wind generators & $\begin{array}{l}\text { Renewable, no carbon dioxide } \\
\text { emission }\end{array}$ & $\begin{array}{l}\text { Use of windy areas, local energy } \\
\text { production }\end{array}$ \\
\hline 3. Natural gas program & $\begin{array}{l}\text { Improve energy efficiency, reduce } \\
\text { air pollution }\end{array}$ & $\begin{array}{l}\text { Supply security, reduce urban air } \\
\text { pollution }\end{array}$ \\
\hline
\end{tabular}

Source: prepared by the authors

\footnotetext{
${ }^{3}$ John von Neumann and Oskar Morgenstern published their book "Theory of Games and Economic Behavior" more than sixty years ago in 1944 . Even on its $60^{\text {th }}$ anniversary it was only a very small group from the professional elite who celebrated the authors even though their work has revolutionalized economic thought. There have been many works from many authors on the economic applications of game theory ever since - but even today, it is the 'imperative to win' that springs to one's mind when games are being discussed. But the most important thing about any game is to know what type of game one is playing. Concerning environmental protection and sustainable development, it is very important for us, environmental economists, to ask ourselves the question: do we know what type of game we are playing?
} 
It is apparent from Table 3 that "environmentalist" arguments for the natural gas programs, biofuels or wind power plants are rather weak ones. Remember: all three solutions have received or are still receiving state subsidies which are labeled 'environmental'. Though any one of them might be useful under certain conditions, all three solutions are marginal innovations only, thus none of them should qualify for unconditional support irrespective of location, time and social conditions. Cost-benefit analyses could yield either a positive or a negative present value depending on the actual parameters. In all cases, results heavily depend on the framework within which they are evaluated.

If and when the measures introduced because of a given decision result in a decrease in environmental capital instead of an increase then it hardly seems justified to talk about environmental protection. The fault lies in the definition of the game itself - in the above cases and in many other situations as well. Mentioning pro-environmental arguments for bioethanol or biodiesel as renewable sources of energy is not exactly reasonable. 'Environmental protection' and 'automobilism' are paradoxical concepts already. One could, however, look into the effects of bioethanol production on employment or rural development and it is quite possible that both cultures along with their upstream industries could qualify for subsidies in that very framework.

The issue of renewable energy sources might be considered an "energy security decision game", accepting the self-sufficiency rate and import dependence to be strategic questions, thus the construction of wind turbines might turn out to be a reasonable choice in this very game. As an environmental protection decision game, however, no sound solution exists to this problem. If we wanted to turn the aforementioned solutions into economically sound choices, we would soon get to the issues of, in the case of bioethanol, GMO's and industrylike production systems, which are taboo to environmentalists (for good reasons, most probably). Wind turbines would lead us to think about water reservoirs like the one planned at Prédikálószék in Hungary (plans for the hydroelectric power station at Bős-Nagymaros included a pumped storage reservoir here in a site of natural beauty in the Pilis mountains), and today's "greens" would for sure not be very enthusiastic about it either. All the above leads us to one conclusion: before participating in meetings to make decisions, we really should consider what type of "game" we are playing and whether we have the necessary competence for the role. Since if we do not know the game or if it is not us who should be sitting there but we still happen to win - that will only bring trouble on all of us.

In Hungary, where there is hardly any wind according to scientific meteorological statistics, the actual installation of the already permitted wind power capacity of about $350 \mathrm{MW}$ seems unavoidable, and investors' expectations are even estimated at several times this figure. Soon, the next "permit race" is about to start. An important question is: what would happen to the Hungarian energy system if, for some environmental/economic policy reasons, the government decided to leave alone the - apparently liberalized, but actually subsidy-driven market?

As environmental economists, we are worried about subsidies for bioethanol and biodiesel production. No matter how hard we try to cover it up, these subsidies are definitely harmful from an environmental point-of-view. These subsidies make fuel cheaper than it would be without them which indirectly fosters the expansion of automobilism - though it should rather be decreased worldwide, and even more so in Europe. It is a known fact that in Hungary the use of bioethanol as a fuel and bringing in wind turbines to the existing electricity system is only possible with strong and continuous state support. 
The real price of energy itself is changing rapidly, yet recently we witnessed substantial price changes within relatively short periods of time instead of the usual few percent fluctuations. From USD 60 per barrel in February 2007, crude oil prices rose to USD 145 per barrel in July 2008. Then a downward trend followed with the price finally dropping to USD 30 in February 2009, yet again bouncing back to USD 70 per barrel by September 2009 (WTI Crude Oil Database 2010). With oil prices above USD 100, pretty much any type of renewable energy seems competitive and rate-of-return calculations in the energy sector indicate incredible opportunities for innovation. Then energy prices had halved in a couple of weeks thus any previous calculations became invalid right away.

Accordingly, Europe and the world have seen the rapid spreading of corn and rape fields during the last two years. Processing plants also started to appear, and then the experiences of one single year turned previous evaluations upside down. And it was not only crude oil prices changing dramatically, but also, something "turned out" that has for long been known by many: biomass is sourced from where our food comes from, thus the two types of land use are in competition. In 2008, bioethanol became very economic because of high crude oil prices and mandatory mix rates artificially fueled the market boom as well. Demand for corn-based bioethanol drove corn prices to heights which poor people could no longer afford, causing starvation in Mexico and in some other regions of the world. Sure enough, there are some who found other explanations. According to New Energy Finance, the use of grain for biofuel production "only" accounts for 8.1 percent of the total increase in food prices. As they put it:

[I]n grains, during the period from 2004 to April 2008, global dollar prices increased by an average of 168 percent. The rising price of oil accounts for an increase of 32.5 percent and other inputs - such as land and labor costs - contributed 7.4 percent. Dollar depreciation accounts for a further 17.9 percent. Supply and demand imbalances account for the remaining 57.7 percent, with biofuels responsible for up to an 8.1 percent increase in global average grain prices (the impact on U.S. corn was clearly above average). The biggest issues were failure to improve yields to compensate for global population growth, along with the failure of the Australian harvest. (LaMonica 2008)

The evaluation cited above did not really clear things up but rather provided further proof that averages tend to cover the truly important matters and that a universal energy policy cannot be right, not even in today's globalized world. An 8.1 percent average price increase does not seem too large, yet in some regions, it might very well be enough for some to die of hunger.

\section{Experiences from a successful alternative thinking business venture. Energy production or rural development?}

Back in 2007, the owners of an existing business decided to contribute to the EU renewable energies strategy: they founded a rapeseed oil mill for producing biodiesel raw material - a true model plant from a sustainability perspective. They employed an integrated approach to all the social, political and economic dimensions and ecological-environmental aspects and thus developed a tailor-made strategy for the given conditions. Sustainability was also accounted for in the location decision-making process. The primary objective was to find an agricultural region where a sufficient amount of rape could be produced in a 50-60 kilometer range, as by minimizing transportation distance one can decrease both transportation costs and the burden on the environment. 
As for all business ventures, profit maximization was the primary goal - but social and environmental benefits were also taken into account, knowing that in the long run, these would actually bring even more serious benefits for the business as well.

The plant started its activities in the renovated buildings of a former agricultural cooperative. Today, it has six employees. Thanks to the processing of 5,200 tons of rape annually and related logistics needs, downstream employment benefits are significant. The plant now has a processing capacity of 430 tons of rapeseed a month, which yields 150 tons (170,000 liters) of rapeseed oil and 280 tons of rape pellet.

The plant we have been presented is located in the Transdanubian region of Hungary and produces crude rapeseed oil, a raw material for biodiesel production. If it was not for the law, this oil could well be used to fuel agricultural and other machines or a power generator, thereby providing for the electric energy needed by the plant itself (i.e. a rapeseed oil-fueled generator). Oil sales constitute the majority of the plant's income. Rape pellet may serve as livestock fodder or be used in pellet stoves as well. Ideally, rape production, oil milling, livestock farming and the energy production infrastructure should all be within a 60 kilometer range. Calculations suggest that approximately 5,000 hectares of rape acreage is what it takes to operate an economically sustainable system. In such a case, there is no need for long-haul transportation and crop rotation becomes possible.

Following heavy fluctuations, the rapeseed market stabilized in summer 2009. The price for rapeseed settled at HUF 63,000 per ton. Considering price and cost levels from 2009, the plant can be operated economically (as 3 tons of rapeseed yield 1 ton of rapeseed oil and 2 tons of pellets): (1 [t rapeseed oil] x 620 [EUR/t] x 270 [HUF/EUR] $)+(2$ [t pellet] x 37,000 $[\mathrm{HUF} / \mathrm{t}])-3[\mathrm{t}$ rapeseed] x 63,000 [HUF/t $]=52,000[\mathrm{HUF}]$.

According to estimates by Oil World (AgroLine 2009), the EU harvested a record amount of rapeseed in 2009. In 2010 the rapeseed crop totaled 20.12 million tons which even exceeds the previous year's record figure of 18.91 million tons. In spite of the above calculations, there is no reason for optimism, as it is uncertain how over-production will affect the market. Neither do we know how slow or fast our emergence from the crisis will be and how that will influence the crude oil market, which, as we have indicated earlier, fundamentally determines rapeseed oil prices.

Table 4. Fluctuations in the prices of crude oil, rapeseed oil and rapeseed as a result of the crisis (2007-2009)

\begin{tabular}{|c|c|c|c|}
\hline & $\begin{array}{c}\text { Crude oil price } \\
\text { (USD / barrel) }\end{array}$ & $\begin{array}{c}\text { Rapeseed oil price } \\
\text { (EUR/t) }\end{array}$ & $\begin{array}{c}\text { Rapeseed price } \\
\text { (thousand HUF / t) }\end{array}$ \\
\hline July 2007 & 75 & 580 & 50 \\
\hline July 2008 & 145 & 1,100 & 110 \\
\hline Dec. 2008 & 35 & 600 & 70 \\
\hline Sept. 2009 & 70 & 620 & 63 \\
\hline
\end{tabular}

Source: compiled by the authors based on data from rapeseed oil millers

Rapeseed oil prices are closely related to changes in crude oil prices as it is shown in table 4 . In July 2007, rapeseed cost HUF 50,000 per ton, while it was already HUF 110,000 per ton at the time of harvest. This figure is not that surprising when compared to rapeseed oil prices which rose from EUR 580 per ton to EUR 1,100 per ton following a similar trend (they fell back to EUR 600 per ton by 2009 and are now around EUR 620 per ton). Experience from the last three decades suggests that it is advisable to buy up at least 50 percent of one's annual 
rapeseed requirement at harvest, when it tends to be the cheapest. This is what the present plant did: they bought up 3,000 tons at HUF 110,000 per ton.

As a result of the outbreak of the financial crisis in August 2008, the price of rapeseed plummeted to HUF 70,000 per ton by December 2008, thus the change in the cost of raw materials alone caused losses of HUF 120 million [3,000 $\mathrm{t} \times(110,000 \mathrm{HUF} / \mathrm{t}-70,000 \mathrm{HUF} / \mathrm{t})=$ $120,000,000 \mathrm{HUF}]$.

The problem is that such businesses are very seriously affected by any change in the world in the economic environment. Everything which is somehow related to agriculture in the European Union is heavily influenced by the EU's subsidy policies. But changes in energy prices, which are influenced by the operation of the economy as a whole, might well be dominated by factors far more powerful than agricultural subsidies - for example, the crude oil price fluctuations between USD 145 and 35 we witnessed during the last one and a half years. This was a strikingly high level of variability for a time span of only eighteen months, no sign of which appeared in any of the forecasts.

Fluctuations of the past three years have by far surpassed anything considered normal, even in the crude oil market - and they are completely new to the agricultural sector, as the costs of agricultural inputs used to be rather balanced. The price of biodiesel, however, is so closely bound to that of crude oil that any radical change in the latter ruins biodiesel initiatives as well. The majority of businesses in this sector are small enterprises, usually with strategic investors. The past two years have proved that businesses founded with the promise of high incomes and government subsidies in mind are doomed to quick failure when exposed to the vagaries of the rapidly fluctuating energy market. Such hectic market conditions could only have been survived by companies who had stable financial investors able to dampen these impacts and to hedge out some of the risks. Local entrepreneurs, having built their businesses on "agricultural potential", however, rarely have financial investment groups as investors. Because of their lack of capital, the immediate sale of the end product - rapeseed oil in this case - is an absolute must for them. Thus it may seem reasonable (only to the "sensibly minded" environmentalist, of course) to ask the question "should production be considered 'local' if the factors for successful production are in the hands of global capital?"

The rapeseed oil mill we introduced would not be of too much interest on its own but given that almost all similar plants went bankrupt, there are some important lessons to learn from its survival. One of them is the existence of the aforementioned financial investor, allowing for a positive cash flow. Another point is that biomass energy production was not the sole purpose for founding this mill. Most rapeseed mills simply wanted to produce biodiesel raw material, thereby taking advantage of the EU policy prescribing the relevant mandatory mix rates, whereas the enterprise we examined aimed at establishing a micro-regional network. They completed a brown-field development to establish a small plant on the premises of a former large agricultural cooperative. By partnering with the former employees (now farming their own land) and suppliers of the sometime cooperative, they enjoyed some benefits which all the other green-field businesses focusing on fuel production could not. Its close relations with agricultural entrepreneurs guaranteed strong local support for the company. The project improved food security (livestock kept on controlled, locally produced fodder), energy security (public institutions heated with rapeseed pellet) and population retention (stable jobs) as well. This mutual cooperation is something rural people can make a living from. If they realize that livestock farming is worth considering, they might very well create the basis for the revival of rural farming activities. Cooperation provides for a win-win situation. Neither a 
rapeseed mill, nor livestock farming or biomass heating seems a promising project on its own, individually. As part of an industrial-ecological system, however, the undertaking as a whole can actually operate economically, and the countryside can also remain a place that is worth living in.

Recent years have showed us that the harmony between the environment and the economy lies with those smaller enterprises which offer significant employment opportunities and thus are desirable from a social point-of-view as well. Considering rural development purposes, bio-fuel production projects might well be worth supporting as they might provide employment for the rural population, improve population retention in these areas and aid in maintaining viable rural communities.

\section{Conclusions}

All the above leads to the conclusion that environmental issues require location- and timespecific decisions, thus international experiences alone are far from being enough. What is good for the US might cause starvation in Mexico. What seems favorable in Brussels might appear undesirable in Hungary, and, what is more, the use of land which perfectly fits the Great Hungarian Plain might turn out to be nonsense for the Transdanubian region. It might happen that rape production remains a rational choice both economically and ecologically for a couple of years, yet later on, it might become explicitly harmful along any one of these two dimensions, or maybe along both. This might seem to suggest leaving everything to chance or to the market (which are quite the same for many, by the way). But there is another possible conclusion: the need for flexible adaptation - a concept also re-discovered by literature, having received abundant coverage in recent years under the name 'resilience'.

Resilience stands for a decentralized or regionalized type of "planned economy" (Walker , as opposed to the centrally-planned system we were used to until Hungary's transition memories of which we might happen to recall when faced with an EU bureaucracy trying to cope with its own managerial challenges.

The need for a sustainable relationship between nature and mankind requires us to focus on ecological flexibility as it primarily deals with the scale of opportunities between stabilization and destabilization: concerning our present development, concerning global environmental changes, the loss of biodiversity, degradation of ecosystems and concerning sustainable development. The concept of technical flexibility, on the contrary, creates the dangerous illusion that environmental systems can be efficiently controlled, consequences can be reasonably estimated and that sustainability objectives can be achieved.

\section{References}

Agroline (2009): Rekord repcemagtermés az EU-ban [Record high rapeseed production in the EU]. http://www.agroline.hu/?q=hir/rekord-repcemagtermes-az-eu-ban, accessed December 30, 2010.

European Commission (2005): World Energy Technology Outlook 2050. Brussels: European Commission, Directorate-General for Research Directorate Energy

Hubbard, H. M. (1991): The Real Cost of Energy. Scientific American 264(4): 36-40.

IIED (1998): Consumption in a Sustainable World. Report of the Workshop held in Kabelvaig Norway, 2-4 June 1998. Oslo: Ministry of the Environment and London: International Institute of Environment and Development.

LaMonica, M. (2008): Biofuels and food prices: Running the numbers http://news.cnet.com/8301-11128 3-9951108-54.html, accessed December 30, 2010. 
Oates, W. E. (1977): Fiscal Federalism. New York: Harcourt Brace Jovanovich Inc.

Rockström, J. et al. (2009): A safe operating space for humanity. Nature 461: 472-475

Smith, V. K - Schwabe, K. A. - Mansfield, C. (1999): Does nature limit environmental federalism? In: Panagariya, A. - Portney, P. R. - Schwab, R. N. (eds): Environmental and Public Economics Essays in Honor of Wallace E. Oates. Cheltenham: Edward Elgar, pp 126-148.

UNEP (1999): Changing consumption patterns. Industry and Environment 22(4): 1-67

Walker, B. (2005): A Resilience Approach to Integrated Assessment. The Integrated Assessment Journal 5(1): 77-97.

WTI Crude Oil Database (2010): Cushing, OK WTI Spot Price FOB (Dollars per Barrel), http://www.eia.doe.gov/dnav/pet/pet_pri_spt_s1_d.htm, accessed December 30, 2010. 